JOURNAL of

MAINE MEDICAL CENTER Journal of Maine Medical Center

\title{
2021 Lambrew Research Retreat; Harold Osher Award for Excellence in Clinical and Population Health
}

Follow this and additional works at: https://knowledgeconnection.mainehealth.org/jmmc

\section{Recommended Citation}

(2021) "2021 Lambrew Research Retreat; Harold Osher Award for Excellence in Clinical and Population Health," Journal of Maine Medical Center. Vol. 3 : Iss. 2 , Article 19.

Available at: https://knowledgeconnection.mainehealth.org/jmmc/vol3/iss2/19 https://doi.org/10.46804/ 2641-2225.1113

The views and thoughts expressed in this manuscript belong solely to the author[s] and do not reflect the opinions of the Journal of Maine Medical Center or MaineHealth.

This Supplement is brought to you for free and open access by Maine Medical Center Department of Medical Education. It has been accepted for inclusion in the Journal of Maine Medical Center by an authorized editor of the MaineHealth Knowledge Connection. For more information, please contact Dina McKelvy mckeld1@mmc.org.

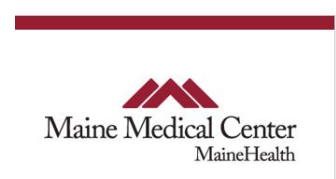




\section{Neonatal Hypoglycemia: A Comparison of Point of Care and Radiometer Glucose Tests Maine Medical Center}

Anna Sagaser, MD; Misty Melendi, MD; Brian Youth, MD; Bridget Manning; Wendy Craig, PhD 


\section{Conflicts of Interest}

\section{The authors of this study have no}

\section{financial conflicts of interest to disclose.}




\section{Background: Neonatal Hypoglycemia}

- Common problem

- Can be asymptomatic

- Can cause derangements in brain metabolism

- Ability to detect accurately is crucial

- Rapid, accurate identification is challenging

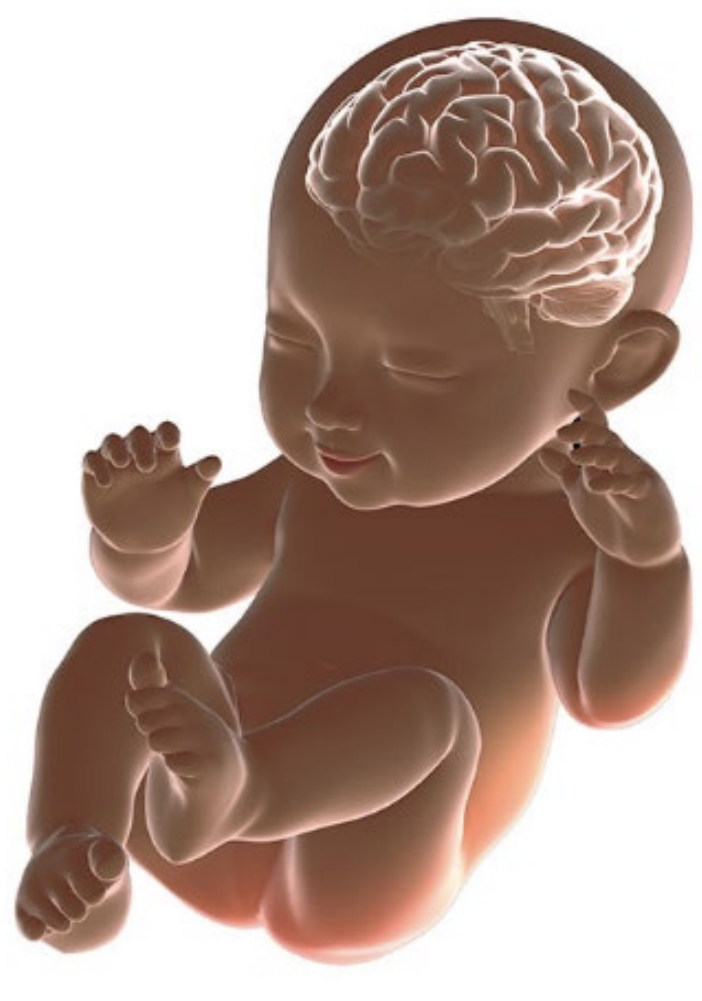




\section{Risk Factors:}

Infants born to insulin dependent diabetic mothers or mothers with gestational diabetes Infants $<2.5 \mathrm{~kg}$

Infants $>\mathbf{4} \mathbf{~ k g}$

LGA infants ( $>90 \%$ ile as plotted on Fenton curve)

SGA infants ( $<10 \%$ ile as plotted on Fenton curve)

Gestational age $<37$ weeks

Discordant twin (weight $10 \%$ below larger twin)

Newborns suspected of sepsis or born to mother suspected of having chorioamnionitis Newborns exposed to any beta-blocker medications

(MMC protocol) 
2018: Nova glucometer was the first glucometer to be FDA approved for use in ICUs, including NICUs

$\rightarrow$ Maine Medical Center recently adopted the Nova meter

\section{...but point of care (POC) glucose tests have not been well studied in newborns...}

\section{Our study:}

We explored whether the Nova glucometer (POC test) provides comparable measurements to the ABL837 Radiometer whole blood gas analyzer (Radiometer Medical ApS, Copenhagen,DK) (ABL test). 


\section{Existing literature on NOVA in neonates:}

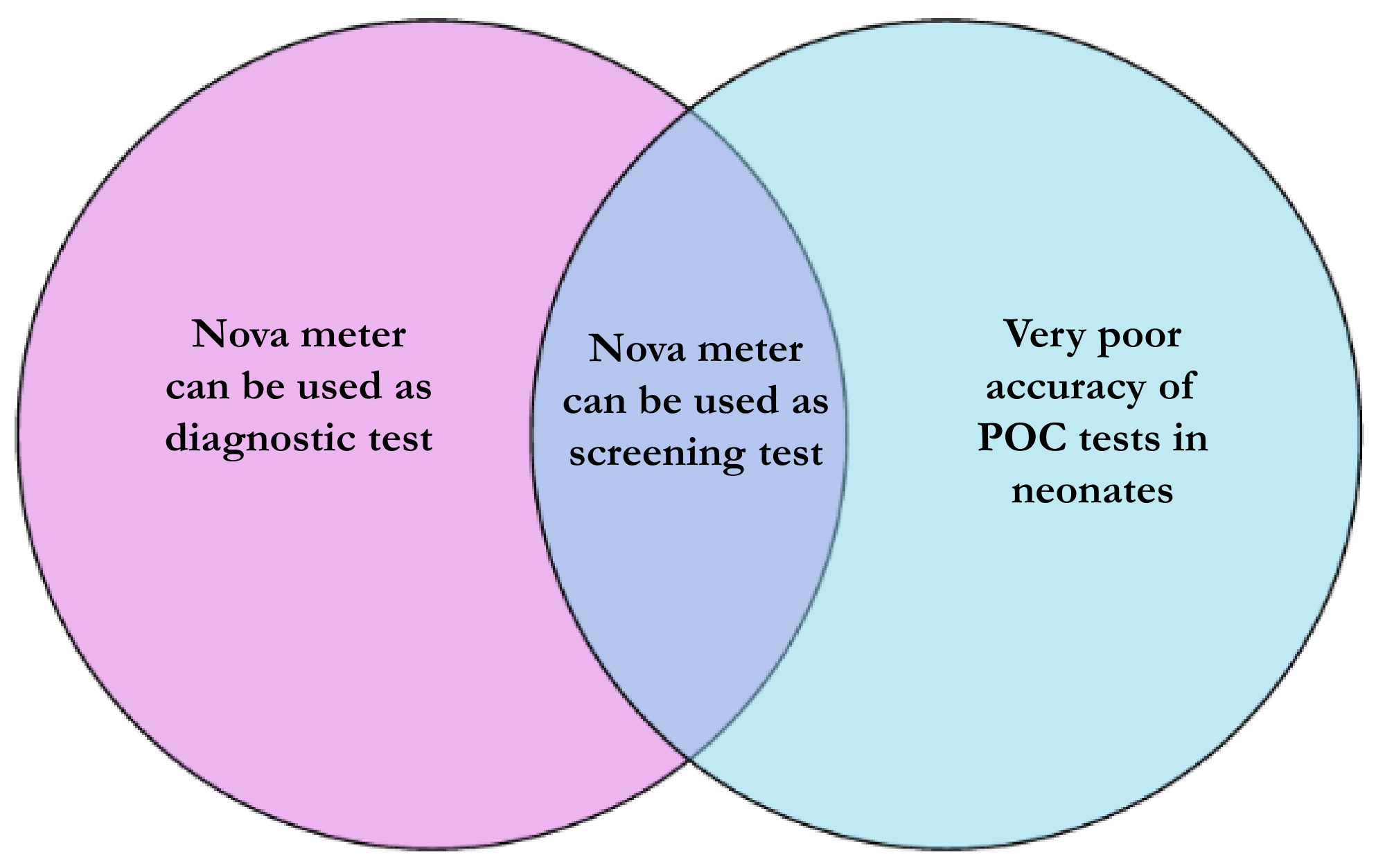




\section{Methods:}

- Collected sample pairs

- Less than 10 minutes apart

- By heel stick

- 704 sample pairs

- September 2019 - March 2020

- Testing done only when clinically indicated (for symptoms or screening)
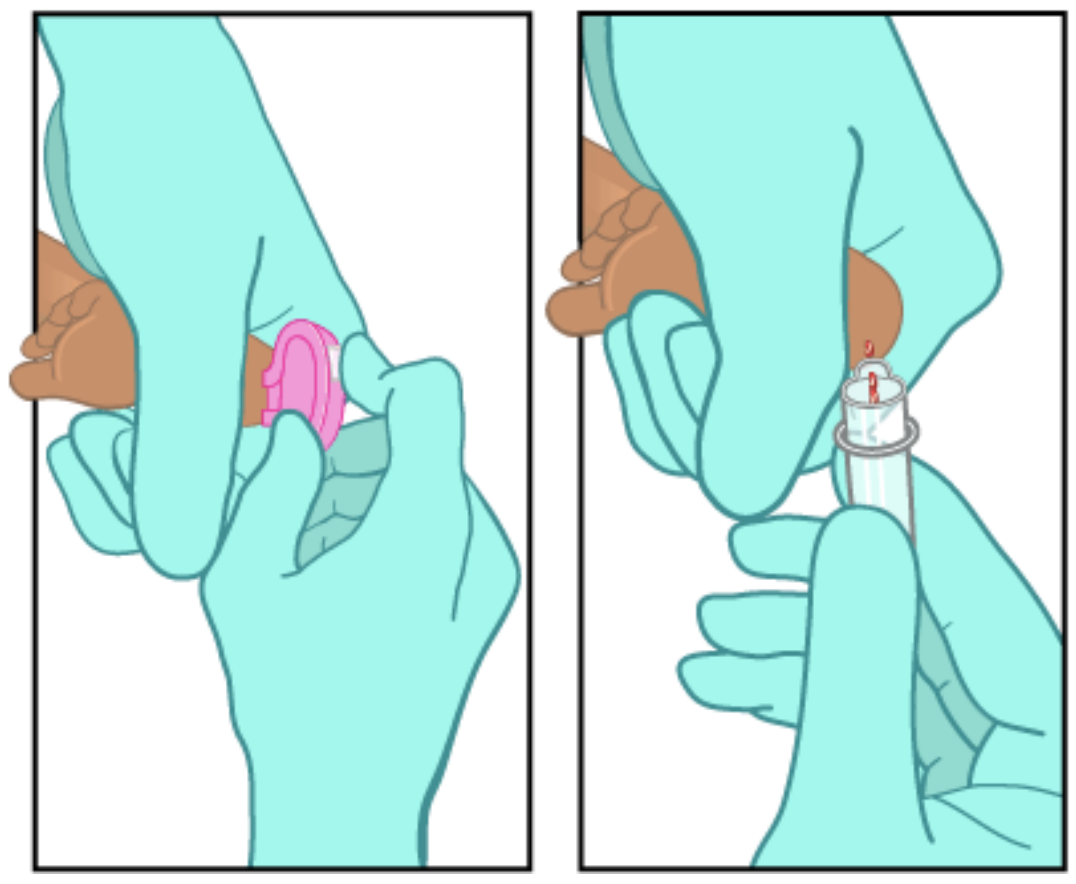

- $1^{\text {st }}$ sample: POC glucose

- $2^{\text {nd }}$ sample: $\mathrm{ABL}$ glucose 


\section{Analysis:}

- Compared results between methods using Bland Altman plot

- Used ABL as the gold standard

- Calculated false positive rate (FPR) and false negative rate (FNR)

for the POC test

- Chart review performed for all false negative POC values

- Hypoglycemia is $<50 \mathrm{mg} / \mathrm{dL}$ 
Table 1: Characteristics associated with the sample pairs

\section{Variable}

$\mathrm{N}$

\section{Location \\ Newborn nursery \\ NICU}

Corrected gestational age at testing (weeks)

$<34$

34-36

$\geq 37$

Day of life

$\leq 1$

1.1-2.0

2.1-3.0

3.1-4.0

4.1-5.0

$>5.0$

\section{Measurement}

704

309 (43.9)

395 (56.1)

$36.9 \pm 2.6$

$67(9.5)$

239 (33.9)

398 (56.5)

$1.7[1.3-2.5](1-72.1)$

$6(0.9)$

445 (63.2)

$130(18.5)$

$44(6.3)$

$12(1.7)$

$67(9.5)$ 
Figure 1: Bland-Altman plot, sample pairs collected 0-10 minutes apart

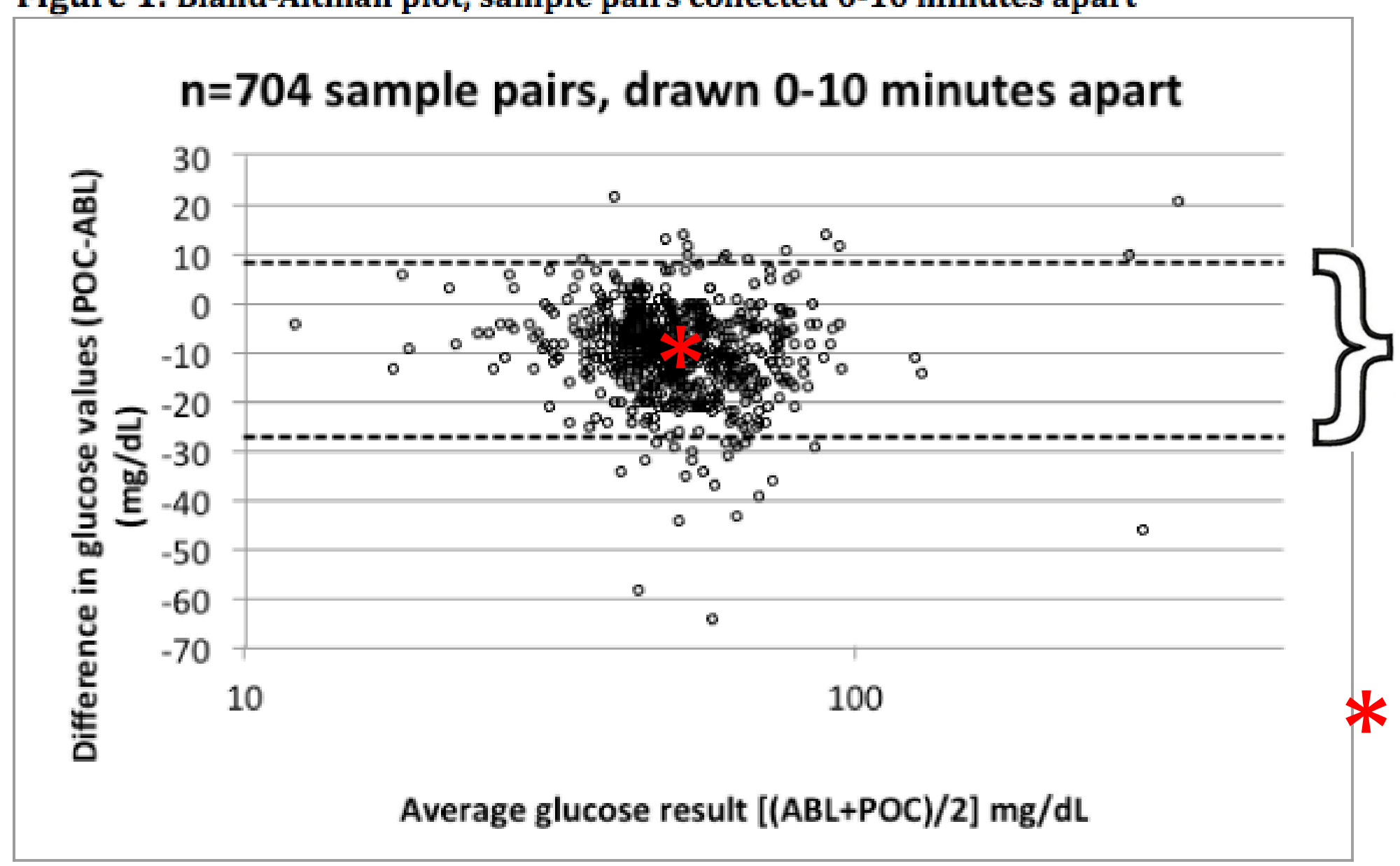

95\% Limits

of

agreement:

-27.4 to +8.1

$\mathrm{mg} / \mathrm{dL}$

$(\mathrm{p}<0.001)$

Mean difference $=$ $-9.6 \mathrm{mg} / \mathrm{dL}$ 
- Average difference between POC and $A B L$ values: $-9.6 \mathrm{mg} / \mathrm{dL}$

- Wide limits of agreement $(-27.4-+8.1 \mathrm{mg} / \mathrm{dL})$

- FNR: $3.2 \%$

- FPR: $55 \%$

- Using an offset factor of $+9.6 \mathrm{mg} / \mathrm{dL}$ :

FNR: $36 \%$

FPR: $18 \%$ 
Table 2: Differences in test interpretation between ABL and POC for sample pairs collected 0-10 minutes apart

a) Unadjusted data

$\begin{array}{lllll}\text { ABL } & \text { POC } & & & \\ & \text { Low } & \text { Normal } & \text { High } & \text { Total } \\ & (0-50 \mathrm{mg} / \mathrm{dl}) & (51-125 \mathrm{mg} / \mathrm{dL}) & (>125 \mathrm{mg} / \mathrm{dL}) & \\ \text { Low }(0-50 \mathrm{mg} / \mathrm{dl}) & 239 & 8 & 0 & 247 \\ \text { Normal }(51-125 \mathrm{mg} / \mathrm{dL}) & 247 & 205 & 0 & 452 \\ \text { High }(>125 \mathrm{mg} / \mathrm{dL}) & 0 & 2 & 3 & 5\end{array}$

b) POC data adjusted by $+9.6 \mathrm{mg} / \mathrm{dL}$

$\begin{array}{lllll}\text { ABL } & \text { POC } & & & \\ & \text { Low } & \text { Normal } & \text { High } & \text { Total } \\ & (0-50 \mathrm{mg} / \mathrm{dl}) & (51-125 \mathrm{mg} / \mathrm{dL}) & (>125 \mathrm{mg} / \mathrm{dL}) & \\ \text { Low }(0-50 \mathrm{mg} / \mathrm{dl}) & 159 & 88 & 0 & 247 \\ \text { Normal }(51-125 \mathrm{mg} / \mathrm{dL}) & 83 & 369 & 0 & 452 \\ \text { High }(>125 \mathrm{mg} / \mathrm{dL}) & 0 & 0 & 5 & 5\end{array}$




\section{Conclusions:}

- POC and $\mathrm{ABL}$ glucose tests are NOT equivalent

- High FPR $\rightarrow$ unnecessary interventions

- FNR of $3 \% \rightarrow$ risk missing true hypoglycemia

- Offset factor makes things worse

- These findings have implications for the choice of glucose testing method in neonates 


\section{Changes in workflow:}

- Using $A B L$ test for all screenings in newborn nursery and L\&D

- Increased use of ABL test in NICU

- Ongoing work to increase workflow efficiency 
Two Site Evaluation of the Performance of a New Generation Point-Of-Care Glucose Meter for Use in a Neonatal Intensive Care Unit (Clinical Chemistry and Laboratory Medicine, 2013) (Tendl, 2013)

Evaluation of "point of care" devices in the measurement of low blood glucose in neonatal practice (Arch Dis Child Fetal Neonatal Ed, 2003) (Ho, 2004)

Glucose monitoring in neonates: need for accurate and non-invasive methods (Archives of Disease in Childhood - Fetal and Neonatal Edition 2014, US) (Woo, 2014)

The Variability of Results Between Point-Of-Care Testing Glucose Meters and the Central Laboratory Analyzer (Archives of Pathology and Laboratory Medicine, 2006, Texas)(Khan, 2006)

Selecting an Accurate Point-Of-Care Testing System: Clinical and Technical Issues and Implications in Neonatal Blood Glucose Monitoring (Journal for Specialists in Pediatric Nursing, 2002, New Jersey)(Sirkin, 2002).

Clinical Impact of Improved Point-Of-Care Glucose Monitoring in Neonatal Intensive Care Using Nova StatStrip: Evidence for Improved Accuracy, Better Sensitivity, and Reduced Test Utilization (Clinical Biochemistry, 2016) (Raizman, 2016)

Blood Glucose Measurement by Glucometer in Comparison With Standard Method in Diagnosis of Neonatal Hypoglycemia (Acta Med Iran, 2014) (Nayeri, 2014)

Point-of-care glucose monitoring on the neonatal unit (Journal of Paediatrics and Child Health, 2011, UK)(Makaya, 2011)

Screening for hypoglycemia at the bedside in the neonatal intensive care unit (NICU) with the Abbott PCx glucose meter (BMC Pediatrics, 2006) (Balion, 2006)

Continuous Glucose Monitoring in Newborn Infants: How Do Errors in Calibration Measurements Affect Detected Hypoglycemia? (Journal of Diabetes Science and Technology, 2014) (Thomas, 2014)

Evaluation of Two Glucose Meters and Interference Corrections for Screening Neonatal Hypoglycemia (Pediatrics International, 2015, Japan)(Wada, 2015)

Clinical Performance of the New Glucometer in the Nursery and Neonatal Intensive Care Unit (Pediatrics International, 2011, Thailand) (Nuntnarumit, 2011)

Assessment of the Performance of Blood Glucose Monitoring Systems for Monitoring Dysglycaemia in Neonatal Patients (BMJ Paediatrics Open, 2018, China) (Ba, 2018)

Su J, Wang L. Research advances in neonatal hypoglycemic brain injury. Transl Pediatr. 2012;1(2):108-115. doi:10.3978/j.issn.2224-4336.2012.04.06 Historical Perspectives: Transient Symptomatic Neonatal Hypoglycemia. William W. Hay (Hay, 2003). NeoReviews January 2003, 4 (1) e1-e5; DOI: https://doi.org/10.1542/neo.4-1-e1

Neonatal Hypoglycemia. Alecia Thompson-Branch and Thomas Havranek. Pediatrics in Review April 2017, 38 (4) 147-157; DOI: https://doi.org/10.1542/pir.2016-0063 


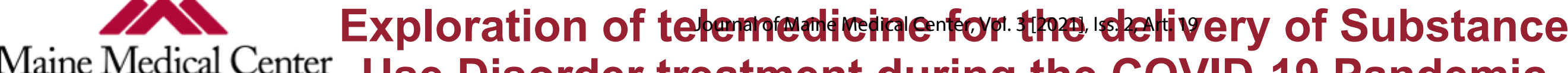

Research Institute Use Disorder treatment during the COVID-19 Pandemic

Maine Medical Center MaineHealth

Rebecca Bell, BA ${ }^{1}$; Hannah Loeb, BA ${ }^{1}$; Michael Kohut, PhD²; Eric Anderson, $\mathrm{PhD}^{2}$; Kinna Thakarar, DO, MPH${ }^{1}$; Rebecca Hutchinson, MD, MPH${ }^{1}$

Maine Medical Center, Portland, ME¹; Maine Medical Center Research Institute, Portland, ME ${ }^{2}$

\section{Background}

- The opioid epidemic has hit particularly hard in rural states where resources for substance use disorder (SUD) treatment options are particularly scarce. ${ }^{1-4}$

During the COVID-19 pandemic, social distancing policies required healthcare providers to turn to telemedicine platforms for the majority of their patient encounters. ${ }^{5}$

- Telemedicine, or the delivery of remote clinical services using phone or video, has been proposed as one possible solution to existing barriers to car access in SUD.

- Preliminary studies have demonstrated promising outcomes for various computer delivered therapy models for individuals with alcohol or opioid use disorder. ${ }^{6-8}$ However, much remains to be understood about the feasibility and efficacy of telemedicine in this particularly vulnerable population.

\section{Methods}

- We interviewed a sample of people who inject drugs (PWID), community partners (CP), and providers ( $\mathrm{Pr})$ who live in and/or provide services in Maine.

- Thirty-six interviews were conducted between April 1 , 2020 and February 28, 2021.

- Line by line coding was performed using MaxQDA by $\mathrm{RB}, \mathrm{MK}$ and HL using inductive and deductiye coding and:apolyng the constant çmparative method to analyze codes.

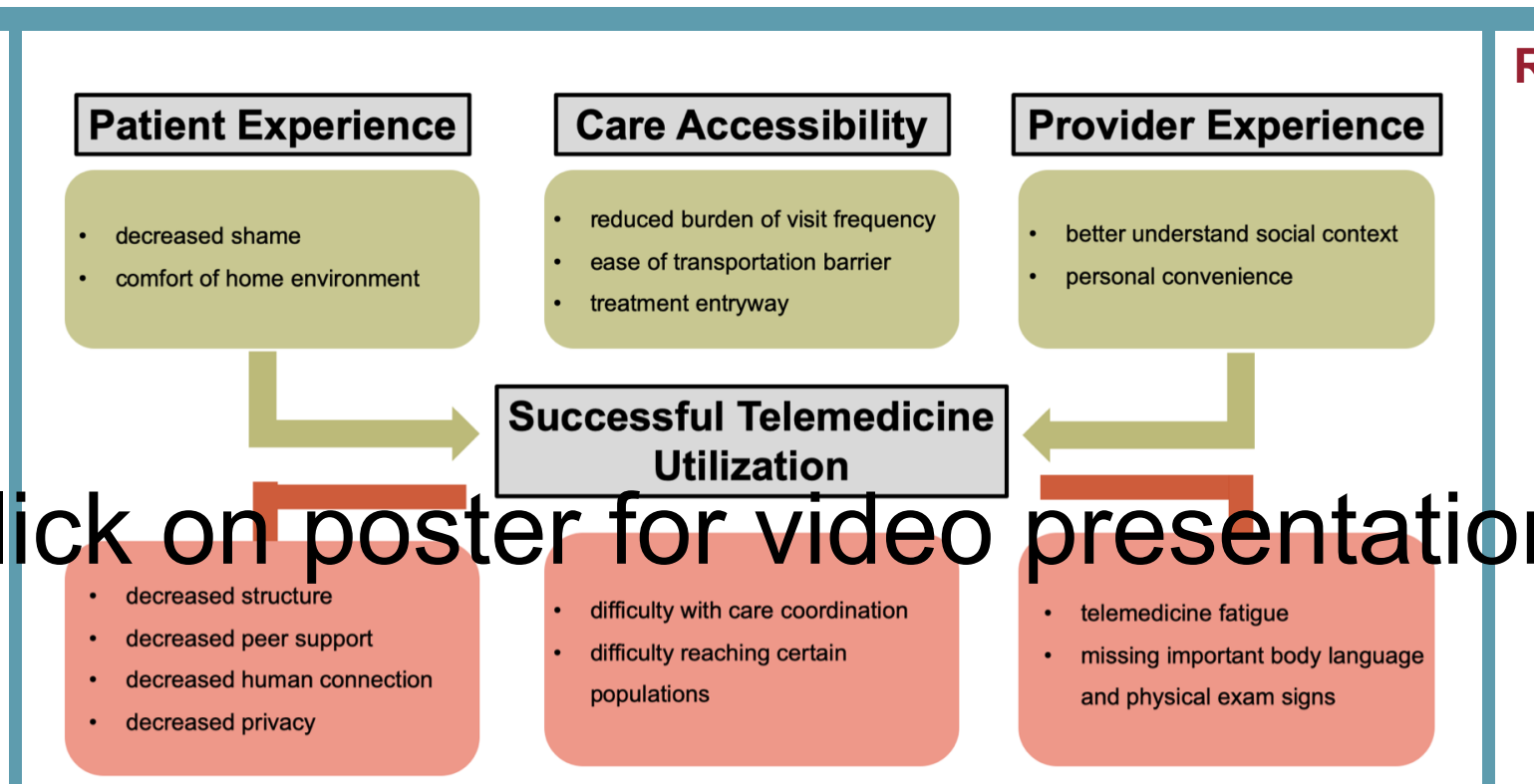

Discussion

- Substance use disorder treatment should not follow a "one-size-fits-all" model.

- Telemedicine offers a convenient alternative that may be useful under certain circumstances and may alleviate some of the existing barriers to care access.

- Some participants expressed concerns regarding making adequate connections over a virtual platform, while others felt well-supported during telemedicine visits.

- While telemedicine has the potential to reduce barriers to care for many, it is important to recognize its capacity to exaggerate disparities amongst more marginalized populations. Accommodating these difference will be critical in more widespread implementation of telemedicine practices.

ss $\$$ Morks Cited

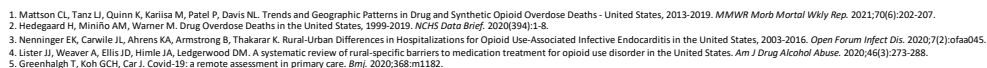

Results

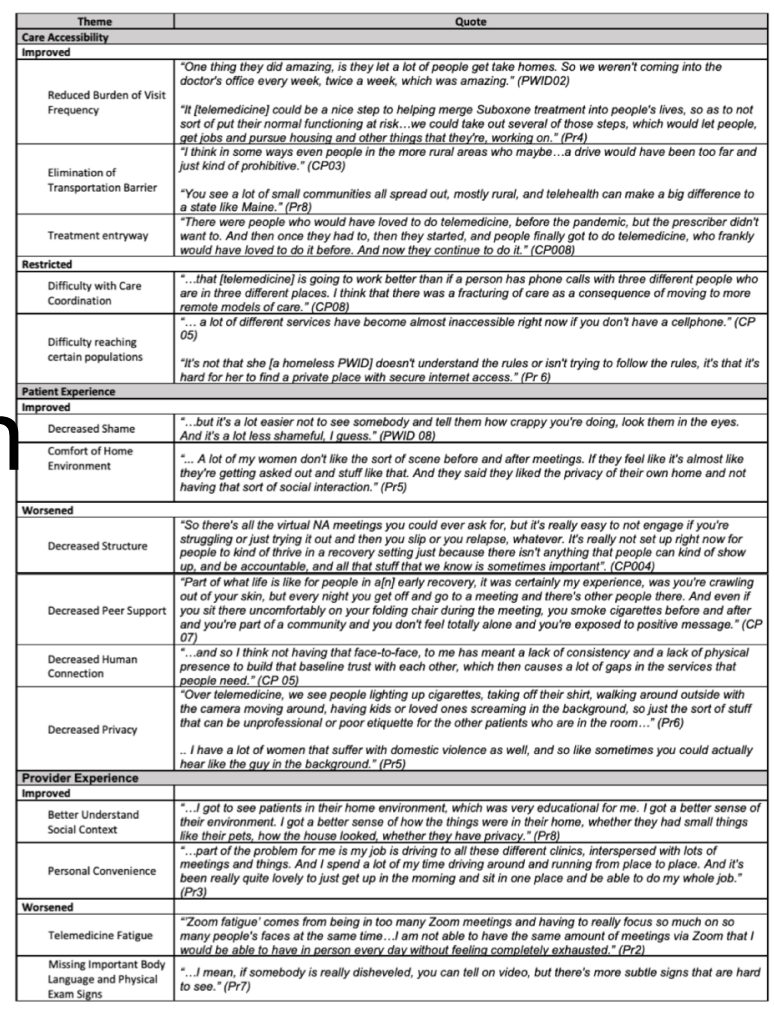

Conclusion

- Telemedicine should be considered a viable alternative to in-person care when patients and providers agree it is appropriate.

- Telemedicine may offer an innovative solution to many of the barriers posed by more traditional 16 models particularly in rural areas. 